\title{
Perceiving the Leadership and Organizational Identity under the Contemplation of Understanding of Psychoanalytical Approach
}

\author{
Ilknur Ozturk ${ }^{*}$, Anjelika Huseyinzade Simsek², Jasim Tariq ${ }^{3}$ \\ ${ }^{1}$ Faculty of Economics and Administrative Sciences, Cag University, Mersin, Turkey \\ ${ }^{2}$ Faculty of Arts and Sciences, Cag University, Mersin, Turkey \\ ${ }^{3}$ Department of Business Administration, Iqra University Islamabad, Pakistan
}

Keywords:

Psychoanalysis, Organization,

Leadership, Organizational

Identity, Management

\section{Received}

10 November 2020

Received in revised form

18 November 2020

Accepted

18 November 2020

*Correspondence:

ilknurozturk@cag.edu.tr

\begin{abstract}
The main intent of the psychoanalytical approach on organizations is to comprehend what happens to individuals who work in groups and organizations and also to understand the effect of organizations on individuals. Understanding the dynamics of organized groups without putting individuality in the background can bring new perspectives to the research and implementations in the area of organizational behavior, management and leadership. This disparate approach can help organizations and individuals within organization to maintain togetherness, and enhance the effectiveness of organizational work which will lead to high performance and success. This paper aims to shed light on leadership, relationship among leaders and followers, and understanding of discursive nature of organizational identity from the perspectives of Psychoanalytical Approach based on works of Freud, Lacan, Bion, etc. In up to date literature, studies on organizational behavior have mostly been carried with humanistic or cognitive and behavioral approach focusing on organizations but the main shortcoming of those studies is that they have not owned in depth investigations and excluded the individuality from their understanding. It is very important to deepen our knowledge on new understandings and practices in the fields of organizational behavior, management, and contribute to the dynamic structure of the modernizing world; future research using psychoanalytical approach can bring new perspectives to the field.
\end{abstract}

@CIKD Publishing

Psychoanalysis is the discipline which examines the different processes, cases, aspects and layers of the psyche, as an efficient cure technique for psychological problems, disorders, and questions. But the clinical practice is not the only area of psychoanalytical theory. The use of psychoanalytical 
tradition in social sciences progressively becomes very broad. As the organizations become different and more complex over time, the emerging theories and approaches of organizational behavior and group dynamics are also differentiated. According to Freud's works (1955a, 1955b) on explanation of group and society, organizational behavior and group dynamics could be interpreted with a psychoanalytical approach. Considered in general terms, the interaction of leaders and followers, identity in an organization could be understood within the basic psychoanalytical terms such as unconscious, transference, projection, introjection, and identification.

When the psychoanalytical paradigm is adapted to organizations, it becomes possible to examine and understand the dynamics of organizations based on the work of many theorists who not only contribute to the expansion of psychoanalytic theory but also to implementations in this field, and not only the psychoanalytic theory of Freud's understanding of human behavior. The main concepts of psychoanalytical understanding of group and society are identity, defense mechanisms, anxiety and unconscious. As a result of the works done in this direction, the theory was first extended to group life by Freud (1955a, 1955b) himself, and later by his followers, especially Bion (1952) and Scheidlinger (1952). Through the psychoanalytical, psychotherapy was applied to the psychotherapeutic communities as well as real communities, the imagination in the bosom of the communities was revealed and their dimensions were discovered.

Perhaps the most relevant question here is: Why psychoanalysis? Psychoanalysis, which is a therapeutic method in the clinical setting, has a comprehensive, explanatory nature, and can lead to many practical applications and shed light on new understandings and perspectives, and provide original knowledge in the field of management and organization. It can extend the theoretical background of organizational research beyond the standards. Despite the usual, traditional organizational research, psychoanalysis is more concerned with hierarchy, authority, and with the emotional, irrational, symbolic and discursive aspects of organizational being.

Psychoanalysis does not just share its view of inner, psychic reality. On the contrary, Freud (1961a) drew attention to "Civilization and Its Discontents" and his theory led to ideas about potential social change. The capacity to discover "external" truth easily compete with the importance of psychic reality and can be considered as facilitating the acceptance of psychic reality instead of moving away from it. The concept of mass psychology emerged 30 years before Freud wrote on group psychology (Hogg \&Tindale, 2008), and it was revealed as a result of the on-going observations of the writers who think that individuals behave differently in the group, crowd, and society.

For the first time, Freud (1961b) in his work "On the History of the Psycho-Analytic Movement" writes about applying psychoanalysis to other fields besides medicine. He referred his own work "Wit and its Relation to Unconscious" (1953) as a first try and example of applying psychoanalysis to the field of humanities. Examination objects of Applied Psychoanalysis are very broad; it includes such topics as group behavior, leadership, internal relationships, management, culture, religion and so forth. The consociate feature of all particular areas is that almost all of the efforts of people as creativity, collaboration, success, learning, etc. are stimulated and bred by the unconscious. In his work "Group in Psychology and the Analysis of the Ego", Freud (1955a) refers to Tarde's concept of "imitation." However, the relationship between the leadership and paternity and the behavior model is more accentuated by Freud. After Freud (1955b) wrote the book "Totem and Taboo", he was extremely interested in how the functions and structures of the psyche are 
related to the history and organization of the family and society. One of the most basic questions he asked: by which instincts and experiences are social behaviors shaped by?

Freud's idea of the tendency to follow the leader Trotter (1941) and Le Bon (1897) argued that a community had a conscious instinct instead of the unconscious instinctive community - the herd. A series of organizational phenomena can be examined from a psychoanalytic perspective. This approach endeavor in this area is to examine organizations as the dominant features of culture and society, to examine their effects on individuals, their influences on individuals' emotional lives, their characteristics in people's fantasies and dreams, relationships such as leadership and authority affiliations, group behavior and harmony, creativity and destructiveness, psychological contracts and obedience.

There are two different aspects of understanding and investigating the organizations with a psychoanalytical approach. First one is, Studying Organizations Psychoanalytically, the pioneers of this approach are Theodor Adorno et al. (1950), Herbert Marcuse (1955), Erich Fromm (1966) and William Reich (1970), and modern researchers such as Sievers (1999), Gabriel (1999) and Schwartz (2011). This perspective appreciates that organizations can be both a cause of excitement and creativity but also a complex source of anxiety and discontentment for individuals. Individual's anxieties, fears, dreams, impulses, fantasies, and emotions are based on their experience as a part of the organization; also, this experience deeply shapes individuals' self-esteem, self-worth, and willingness to engage with others, beneficial business skills, interests, and perspectives.

The second aspect is Psychoanalyzing Organizations which sees psychoanalysis as a psychological intervention applied to organizations and considered as an organizational intervention method to improve and develop organizational functioning. The psychoanalytic psychotherapy method, the individual psychoanalysis, aims to help the analyze and overcome the concerns and difficulties by gradually becoming aware of the unconscious content of the analysis and, and bringing a compromise with these contents. In this case, is it possible to attempt a similar intervention to the organizations? If it is possible, then to what extent is it functional and serve the purpose? Such interventions are possible by revealing suppressed unconscious forces such as the fear of competition, losing and failure, anger, betrayal, disappointment, cooperation, creativity, harmony, and the emergence that significantly affect their performance within the organization. It identifies individual pathological processes such as megalomania, self-deception, paranoia, and anxiety, which instantly reflect homologous processes between persons, within the organizational structure, thus revealing that the entire organization is affected by neurosis in a certain way. Such a neurotic organization infects anyone who contacts with it as a worker, as a collaborator or insomuch as a leader. A few researchers working on organizations with this approach go a step further and suggest that it reflects the organization, the individual psyche, and especially the leaders. Therefore, they are equipped with concepts such as an organizational unconscious, executive organizational ego and organizational superego, whose dynamics, compromises and dysfunctions are reflected individuals. The pioneers of this approach are British and American psychoanalysts. The contributions of the British Psychological School, the majority of M. Klein's followers working at the Tavistock Clinic and the Tavistock Institute, were crucial. In 1946, in London, the Tavistock Institute of Human Relations was established by the group of famous psychoanalysts of that time, Wilfred Bion, Melanie Klein, Elliot Jacques, and John Bowlby. This group, in light of previous works of Wilfred Bion (1952) on group unconscious, worked on the hidden dynamics of organizations and their effects on leadership mostly in public organizations 
such as hospitals. Elliot Jacques with his partner businessman Wilfred Brown (Brown, Brown, \& Jaques, 1965) carried out a 17-year study titled "Glacier Project" at the factory, examining organizational dynamics of the factory (Fraher, 2004). Tavistock Institute is still working on the psychoanalytic and psychodynamic understanding of organizations and groups. Wilfred Bion (1961) has made the biggest contribution to the field; providing a psychodynamic model of the "social individual" in organization/at work: showing how person internalized the feel of character of the organization in which he works, and at the same time projecting his unconscious desires and anxieties into the organization. In USA Levinson (1987) Levinson, Molinari and Spohn (1972) and Zaleznik $(2004,1989)$ can be counted as the pioneers of this approach.

Both approaches have developed a series of psychoanalytic interventions in different ways that aim to help identify and address organizational dysfunctions caused by leaders and followers' interactions. The Studying Organizations Psychoanalytically approach is theoretical, conceptual and abstract; the Psychoanalyzing Organizations approach is more applied and interventionoriented. The Studying Organizations Psychoanalytically approach deals with rigor and generalizability, while the Psychoanalyzing Organizations approach deals pragmatically with results and effectiveness.

The most important distinction between these two approaches is related to the character of the investigated conflict, both in the context of psychic and organizational conflict. While the Studying Organizations Psychoanalytically approach follows the work of critical theorists like Freud and Marcuse, they suppose that almost inevitably within the existing social organization of neurotic symptoms, concerns, and dysfunctions that accompany most of the conflicts. The Psychoanalyzing Organizations approach addresses each of the conflicts as a separate phenomenon and as a result of dysfunction, when some management processes fail and therefore evidence that it can be corrected. While the drawbacks of this approach consider both individual and organizational neuroses as preventable and curable, followers of the Studying Organizations Psychoanalytically approach are more skeptical, based on the clues from Freud's theory. In some cases, followers of the Studying Organizations Psychoanalytically approach maintain that organizations, even if most of the members of the organization are unhappy, anxious, or properly neurotic, can function quite effectively. Some neuroses (workaholics, compulsions, paranoia, etc.) can be quite useful and functional for organizations in some cases. Both approaches have important contributions in understanding the way organizations operate, their dysfunction, dynamics between employees and leaders, etc., both theoretically and practically.

The main purpose of this paper is to draw attention to psychoanalysis as a theory with an expansive range of descriptive capability and the potential to make over-thinking according to organizational practice in new ways. The motivation that affects, identifies and changes the lives and functioning of organizations, interpersonal and inter-group relations, organizational culture, organizational identity, change, the development of strategies, are often examined by observable behavioral approaches, but not only those who are invisible to examine and understand them. The use of psychoanalytical approach will allow researchers to see the organizations and their dynamic in a new light, and suggest a new implementation for management practice.

\section{Psychoanalysis}

Psychoanalysis is the name used by Freud in 1896 to describe the clinical method used for the treatment of neurotic disorders. When it first emerged, it was very radical, innovative in its own time, based on conversations between the patient - analyze and and the therapist - analyst. During 
this conversation, the patient is encouraged to say his thoughts and ideas aloud to the analyst, to say what comes to his mind without applying any censorship or control, and to be told by the free association method. The discovery of the discourse that emerged in this process allowed to examine the material of the patient's unconscious, which forms the basis of his conscious experiences such as perceptions, emotions, judgments, decisions, and desires.

Besides, Freud and his followers' theoreticians contributed to the development of different critical theories that address and influence the work of culture, politics, and organizations. Psychoanalysis has contributed to many disciplines and gained new perspectives for sociology, aesthetics, linguistics, music, art, philosophy and psychology, which have become the most important and effective theory of the century. In the last 100 years, psychoanalysis has become a popular theoretical flow. Freud's unique and powerful influence gained by being the "father" of psychoanalysis became increasingly known.

Psychoanalysis, which started as clinical practice, was the first to develop the theory of the unconscious, which is discussed as both normal and pathological. The concept of the unconscious is a part of the human psyche that affects the behavior and organizes the personality; affects every aspect of human psychology. Initially, Freud mainly focused on individual behavior and the therapeutic effect of psychoanalysis, in time as his theory evolves, he pursues to understand the groups and societies in the light of psychoanalysis. In 1912, he published "Totem and Taboo" which was the basement of analysis of anthropological issues in terms of psychoanalytic theory. Totem and Taboo are Freud's first theoretical texts on communities and social bonding. The subtitle, "The Similarities in the Psychic Life of People with Neuroses" gives us information about Freud's method: to compare the features of the psychic phenomena of the neurotic person with the psychoanalytic experience and to underline the archaic features of modern man. The text is based on the analysis of primitive civilizations, the source of some of the peculiarities of the functioning of social communities, just as the psychoanalysis of the source of the dreams to understand the psychic functioning of neuroses. Freud argues that the development of these primitive societies and the common aspect of personal development is the Prohibition of Incest: as in human development, communities organize and develop around the law following the rules arising from that law. The Oedipus Complex describes the humanizing and constituent 'drama' in which the child is opened to society and forced to open to society through mediation to father and the proximity to his mother, which is almost bodily. The reunion with the forbidden mother is way back to the mother. This ban organizes societies as well as organizes psyche. He explains the beginning of morality, religion and social organization by basing on the narration of the first group of people he called "primal hoard", (Freud, 1955b). To justify this idea, Freud proposes a Myth of Primal Hoard, which is much discussed by anthropologists in a later period. According to this myth:

Human societies were ruled by a ruthless Chief of the Hoard. This cruel chief embraced all the women of the hoard and killed his sons one by one when they become old enough to deprecate him. One day, the brothers organize among themselves and kill the cruel father. Then they eat the father with a totemic feast and lay the foundation of the first social contract. Women will no longer be shared, and the relations between them will be bounded and framed by the rules that describe these boundaries. Eating the father also means having each of his powers, and Freud identifies the basis of the phenomenon of identification in this cannibal feast. 
The first social bond is established in the shadow of this murder. The primary dream at the heart of the social organization is the murder of the Primitive Hoard Father. Although Freud's argument has been much debated, from a psychoanalytic point of view, an important and constitutive "law" for the psyche is the acceptance of a Prohibition by a community and the emergence of categories that distinguish between possible and impossible.

A second text in which Freud analyzed the functioning of communities psychologically is "Group Psychology and Ego Analysis". The social background of the text, published in 1921, is the bloody First World War, in which national identities emerge, and the behavior of people in the community is the research area of the social psychology of the time. Freud was highly influenced by Gustave Le Bon (1897), who argues that there is an interaction between society and the individual. He says that individual psychology is a direct and at the same time social psychology, and asks the question: "what unites communities, masses, societies?" A community is a certain number of people who have substitute one and the identical object in place of their ideal self, Freud says in his text. Of course, there is a model of the brothers' community that has signed a contract as in the Primal Hoard. Freud explains the change that one has undergone in the community with the mechanism of identification. Although Le Bon (1897) describes the phenomenon of identification as a kind of imitation with the concept of mental contamination within the community, Freud treats it differently. Identity is not imitation, but the living, feeling, behaving of the identified person just like the hysterics. Of course, this phenomenon is unconscious. Communities examined in the text, are artificial and organized communities such as the Church and the Army, as well as ordinary communities are included. In these latter kinds of communities, the charismatic person who drives the community is identified in a narcissistic and uplifting way. Emphasizing that the prototype of such identification is hypnotic, Freud expresses his attention to communities in some way; or at least an understanding is possible: community is the place where artificial exaltations, hypnotic stupor, individuality disappear. This primitive connection that arises in the unorganized communities with the power of hypnosis is at a level that can lead to all kinds of deviance and violence.

Freud (1955a) in his "Group Psychology and Ego Analysis" work, explained what made the group a group, the nature of the bond among group members and the role and influence of the leader on the group and internal bonds and attachments. There are three main considerations why this work of Freud is very important for comprehension of group or organizational behavior: presents an original and coherent theory of group work within the framework of Freud's psychoanalytic theory; provides ideas that have become the starting point for those working in this field and make great progress; shows how much psychoanalytic thinking is interested in psychology of society (human in relationship) and individual psychology (human as a unique personality). Psychoanalysis is under an obligation of the premise that on a large-scale mental life is unconscious. Emotions, ideas, and desires are unconscious, and they are products of psychological defense which is avoiding the suffering of the anxiety-provoking thoughts and feelings. What cognitive and behavioral psychology explains as motivation, psychoanalysis explains as desire, motives, and desires are unconscious? Unconscious desires, which may be a chase to an earlier life, if they are not realized, they substitute themselves as conscious desires, such as career desires, material object desires, etc. 


\section{Psychodynamics of Leaders and Followers in Group}

The leaders both cause and support changes in the behavior of organizations, groups, and teams, or individuals. To use leadership efforts, studies and practices effectively, it is important to know how these changes will affect and work at structural, procedural and behavioral levels. Often, the leader's efforts in this direction - purposeful, planned and conscious, but in some cases may also come from unconscious understanding.

There are a very insufficient number of studies with a psychodynamic and psychoanalytic approach to leadership. Traditional approaches to leadership are often studied within the framework of behavioral or humanistic concepts, and the main focus of these studies is on the concrete and measurable aspects of leadership (Davis \& Luthans, 1979; Gardner, 1989). One of the most important and frequent criticisms made by studies with a psychodynamic and psychoanalytic approach is the ignorance of hidden, unconscious dynamics affecting the behavior of groups by researches conducted with a behavioral and humanistic approach.

If the studies in the fields of organization, leadership, and management are examined from a psychodynamic and psychoanalytic point of view, it also makes leadership and management in organizations more comprehensible, gives the opportunity to examine more closely and offers a new perspective for the applications.

Leadership is a highly complex interaction between people in different positions, contexts, and systems. The leadership can be explained as the behavior of individuals and organizations, the establishment and strengthening of relationships, coping with conflicts, creating a commitment, building group identity and increasing effectiveness (Kets de Vries, 2001). The greatest deficiency of observations, implementations, and studies on organizations, can be emphasized as the neglecting of such important points as the unconscious life of organizations, effects they have on the big group, business and political behaviors, social dynamics (Kets de Vries, 2006). The psychodynamic perspective of the flow of life in organizations will help us understand and clarify the changes that leadership has suffered, its victimization, positive and negative phenomena.

In organizations and groups, it is often leaders who both support and change the behavior of individuals. In order to work on leadership, to improve the functioning of organizations, to make them more effective, it is necessary to examine the structural, operational and behavioral dimensions of organizational dynamics in depth. Mostly, the leader's efforts to influence and change the organization are purposeful, planned and conscious. But in some cases, it may be less conscious, and unconscious. A small number of psychodynamic and psychoanalytic studies (Hirschhorn, 1990; Trehan, 2007) have been conducted to understand leadership and the fact is that they are conducted in very limited areas constitute a deficiency in this field. Traditional leadership approaches are generally conducted within the framework of behavioral and humanistic theories, focusing on the concrete and measurable, observable aspects of leadership (Ivancevich \& Matteson, 1999; Sharma et al., 2019). The main point is that these studies reckon without the hidden dynamic of groups that affect organizational behavior, on account of this psychodynamic and psychoanalytic understanding will provide a broadened understanding of leadership, behavior, and management of organizations, and give a new vision for applications.

McDougall (1921) claimed that previous studies mostly focused on crowds or unorganized audiences. He admitted that the individual was attracted to such masses by the principle of "directly caused by emotions" through primitive sympathy. He also agreed that the unorganized crowd could develop strong emotions in everything that contributes to the suspension of conscience, which 
causes, sensuality, but argued that the organized masses are different. Although Freud acknowledges this difference, he considers that McDougall's proposition is not enough to answer the nature of harmony and where it comes from, so he shaped the focus of his book "Group in Psychology and the Analysis of the Ego" around this question. The main interrogation of that book was the internal representation of social constraints and the nature of close ties between followers and leaders. One of the questions that Freud asked first and focused: Is it possible that the mass exists without a father figure, or does the mass quickly break down without it?

Freud, in his book "Group Psychology and the analysis of the Ego", interprets and discusses the works on group psychology of Le Bon (1897) and McDougall (1921), and reveals his thoughts according to "psychological group" or "collective mind" as follows: before a random crowd of people can come together and form a psychological group, the main condition must be met: to these individuals there must be something similar to each other, to have the same attention to the object, to have the same emotional prejudice to a situation (Freud, 1955a).

To shed light on group psychology, Freud used the term "libido", he describes the libido as psychic energy within the word "love", in groups individuals are attached to each other with emotional bonds, that are evidence of libido. Freud used two different groups to explain emotional ties in groups, Church and Army, both of them have a leader: Messiah and Supreme Commander. In both groups, members have an illusion that their leader loves each of them equally; each member of the group forms a libidinal tie with the leader and other members of the group. One of the emotional ties that dominate groups is the tie with the leader and a more prescriptive tie that holds the group members together. The identification mechanism is involved in the functioning of this libidinal process. According to Freud, the identification can be explained as an individual's desire to resemble the object /the other, as Freud explains in his work, a little boy would like to be like his father. After the model is identified, it takes an effort to shape the individuals' ego. The Ego takes on the properties of the object. In the identification, the father becomes the precursor of an object bond with him; the ego sometimes imitates the loved and sometimes unloved objects. We can see that identification after a model is formed, strives to shape a person's ego. In epitome, identification is the oldest and most actual form of emotional bond; identification in a regressive path becomes a substitute for a sensual object bond by internalizing the object in the ego; identification can occur with any new perception of a common feature shared with a person who is not the object of sexual desire. The more common this common feature is, the more successful the identification is, and thus represents the beginning of a new bond.

The interdependence of members within a group is the nature of identification, which depends on a common important emotional trait, and we can assume that this common trait stems from the natural bond to the leader. The identification is shaping the ego, "the shadow of the object falls on the ego", and here the internalization becomes clear. Freud called this "ego ideal," and through its duties, individuals attribute to him features like self-observation, moral conscience, and so on. The ideal of the ego is the heir of narcissism childlike ego that enjoys self-sufficiency. It brings together the effects of the environment on the ego day by day.

Also, Freud refers that the identification establishes purposive attachment between members of the group and cohesion with a leader that construes the psychological bonds among followers. Group form, according to Freud, when individuals are tied around an accepted and desired object; group lasts when all members reprieve an achievement to that object. Repudiation of desire leads to the continued idealizing of the object by all members, so they maintain the "safety of never losing 
the object of their desires" by forming a psychological tie with each other. In the process of identification, the individual wishes to be like an object, and "introjects" that person into the ego. The concepts revealed by Sandor Ferenczi (Ferenczi \& Jones, 1916): "introjection" that discloses the process when an infant tries to make pleasurable experiences part of his self and "projection" when unpleasant and painful experiences are removed away.

In relationships with others, the process of mirroring gives individuals important cues according to the behavior (Kohut, 1985). In groups or organizations, the process of mirroring becomes a collective transference phenomenon. Leader, replaces caregiver, followers use leaders, they project on leader what they wish to see, leaders approve the projected. As a result of this process, leaders behave in accordance with their image projected by followers instead of fulfilling the main needs of the organization. The idealization is one of the main needs of self-development, is a need to create an idealized image of significant others, as a result of this infant experience a sense of fusion with created idealized other. This idealized other is perceived as strong, confident, powerful, as a result of that sense infants obtain a feeling of freedom, safety, and security. Thus, infant internalize caregivers, and this powerful, ideal caregiver's qualities become the own qualities of infants' self, idealized transference provide a protective shield to the self (Kohut, 1984). The most important of the positive aspects of idealization and reflection within the organization is that it keeps the members of the organization together in crises and lies at the basis of building a strong bond, create a common perspective, temporarily suspend insight, and ensure that group members act with devotion.

Harter, Ziolkowski, and Wyatt (2006) maintain that the leadership process is formed on inequality among leaders and followers. Coincidental suspicion also has been made by Gabriel (1997), he explains that the followers need to "go up" and leaders need to "go down" to meet each other. According to particular theories, leaders have been contemplated as an individual, whereas followers are assumed as a group or horde. Leaders are always designated as singular, unique and very different from followers. "Following" as a term is a mirror image of such presumption, that point the psychological inequality among followers and leaders, as Harter et al. (2006) proffer in their article. Current theories of management and leadership maintain a stinging distinction among individuals without considering the social impact that may have any effect on individuals' psychology.

Freud (1957) in his "On narcissism: An introduction" work, focused his attention to the relation between external objects and libido, trying to explain and understand this relationship and he put forth the concept of "ego-ideal", he continued to work on it and finally, he accentuates it in "Superego" in 1923 in his "The Ego and the Id" essay. Based on this discovery, he postulated that in organized groups followers substitute their ego-ideal with a leader. The question Freud wants to know is: how do leaders ensure compliance in organizations? The answer to this question can be found in the concept of Eros. The limitation of narcissistic love can only be achieved with love directed towards others.

Freud (1955a) explained in-group narcissism and the narcissistic connection amongst leaders and followers. Freud's conceptualization of narcissism is decisive to understand the influence way of external objects on the person. Freud describes a stage of primary narcissism as "a developmental stage" in whichever there is no differentiation among the external and internal psychological world for the person (subject). The secondary narcissism, according to Freud, is a redirection of primary narcissistic drives on to external objects pursuant to social norms; the subject begins to await other 
people psychologically. Narcissism, particularly the move from primary to secondary narcissism, is therefore fundamental to understanding the modality and exigency for the formation of groups or organizations.

Freud explains his verdicts after discovering a lot of psychological processes that unveil the impact of narcissism with social interactions. As seen from the Freud's' decisions, secondary narcissism maintain the psychological ties to retain individuals. To elucidate continuation of groups, Freud analyzed two aspects specifically related to group ties: Identification and Idealization, they abnegate psychological autonomy of the person by transferring narcissistic libido upon exterior objects (Freud, 1955b). Just before World War I, in 1941 British surgeon Wilfred Trotter had revealed exactly what my "herd" instinct meant. Freud brought up his concept of Superego over this concept and pronounced identification as a central psychosocial process (Rosen, 2006).

Many theorists state that narcissism underlies leadership (Freud, 1955b; Kernberg, 1975; Maccoby, 1976). Freud (1955b) explained narcissism in many ways. From the meta-psychological aspect as a stage of psychosexual development, the source of ego and self-esteem establishment, and he called it "primary narcissism". Narcissism, as a dimension of personality, is concerned with how an individual looks more than how he feels, striving for power and control, focusing only on own interests and self-dominance. Narcissism is conceptualized as pathological and nonpathological.

Non-pathological - normal narcissism is an individual's adaptation with himself, environment and other individuals; experiencing the feeling that the environment can meet his expectations. At that point, self-esteem and self-confidence of the individual are superior as possible, devoid any suspicion and the criticism or any impact (negative or positive) from others are minimized. Individuals with pathological narcissism are completely self-confident, they behave in the manner that they do not care about others' thoughts, but in the internal process, they are open to feeding with the thought of others. This indicates that these individuals in their internal processes do not trust themselves, contrary to their exaggerated confidence in appearance and attitudes. The most significant matter in pathological narcissism is individuals need and openness to be fed with completely external interpretations.

Narcissism offers the integrity and loyalty of the work done by the leaders, the leader's strong worldview, the flexibility of this view when necessary, and provides a basis for identifying and clinging to his followers. Narcissism, which is essential to the success of the organization, can sometimes become toxic and destructive. Narcissism can be defined as constructive and reactive: Pathological reactive and non-pathological constructive. Constructive narcissistic leaders can be described as well balanced, with a sense of self-esteem, with a good-enough sense of empathy. They help others to be better. Reactive narcissistic leaders concenterate their entity on such issues as superiority, prestige, and power. Their main drives are always to achieve the top; they never are eager to share the power, they are highly responsive to admiration. These leaders are unable to cope with criticism; they are rarely taking other's advice. Identification with aggressor - to cope with the anxiety of a leader's toxic and aggressive behavior, sometimes followers use the defense mechanism described by Anna Freud (1936) and Sandor Ferenczi (1988) as identification with the aggressor. To protect against the possible damages of the attacker, individuals imitate aggression and transform themselves from threatening to threaten. They harm the group, find themselves the 
scapegoats in the group, and arrogate everything on them in the group, so they become the group's external identity and internal control balancers.

Organizational life, resound with the earliest experiences of every group member, in relationship with superiors or leaders, very often emotional experiences are reworked in the way they were with parents, at the early stage of life. Other very important early feelings are aroused and result in anxiety, and that leads group members to undertake psychological maneuvers, defense mechanisms, which are used to reduce anxiety and painful feelings, which lead to difficulties to work with others (Jaques, 1995). Individuals, project painful fears and anxieties into the other, Klein (1946) conceptualized this process as "projective identification". Dysfunctional organizational relationships established in that way, in the mild form, may build up empathy, sensitivity, and understanding of each other. On this basis, the works of Bion (1961) explain that organizations and groups have unconscious mental processes that are repeated through all groups and group members, and also organizations have unconscious life. Like individuals, groups, effectuate different destructive emotions, anxiety, guilt, and envy. When a group as a whole is unsuccessful to handle those emotions, they become unable to finish the tasks or achieve the aim they had to. This was named as "basic assumption functioning" by Bion (1961), that can be explained as a collective defense mechanism, that goal is to extenuate group anxiety. This assumption of functioning is archaic and rooted in the prenatal period lasting to the early childhood period. There are three main assumptions assigned by Wilfred Bion: dependency, fight-flight, and pairing. Bion says that without being aware, any group follows three basic assumptions, respectively.

Dependency. Any organization when processed in accordance with this assumption, for its psychological nutrition, asks the leader to whom it is dependent to protect it. If the leader does not accept the power and duties that arise from his role attributed to him, the community cannot survive without conflict. Although the result is not bad, the community has not experienced radical progress. If the leader of the community does not accept the role sought, he feels abandoned and disrupted. Sense of insecurity prevails among members of the community. The dependency on the leader manifests itself in the community at first with a long silence and difficulty in finding topics to discuss; the community expects the leader to propose. Dependency responds to one of the eternity dreams of communities, which is a good, strong and intelligent leader who takes responsibility instead. Just like in childhood, the first child dreams that dealing with reality is not the child's work but the parents themselves.

Fight-flight. The leader's refusal to accept the assumption of addiction poses a danger to the community, which thinks they can no longer survive. In the face of this danger, participants often come together to fight or escape. From this point of view, the fight-flight attitude shows that the community is in solidarity. Community members facing common danger stay closer to each other. Pairing. The fight-fight attitude occasionally results in sub-assemblies or pairings. Group aim is "as if" match the members into pair, to create a new leader, unborn leader - Messiah. This pairing is based on hope, hope that this Messiah will protect them and reduce their fears and anxieties. This match may also aim to rebuild the entire community, but this match is dangerous to the community as it tends to form an independent sub-community. As the group prospers in creating the leader, hope weakened. All assumptions are the defense mechanisms of the group. The dynamics are working only in that certain group (Jaques, 1989). The three basic assumptions mentioned here do not emerge at the same time. One of them outweighs and the other two curtains, they remain in the 
state of hidden power. They form an unconscious system. According to Bion, the true leader of the community is a real part of the community and is the one who shares the beliefs of the community. He does not have to convince the community of his personal beliefs (Stokes, 1994). The leader needs to be a little distant; he must be both inside and outside the community. The interaction and relationship between leader and followers, and also the productivity and effectiveness of the organization depends on individuals' subjective perception of organizational identity.

\section{Organizational Identity}

The notion of organizational identity has been accepted as the basic and important concept of organizational studies in recent years. Organizational identity is how the members of the organization characterize themselves as a social group and express themselves differently from the other organizations' members (Empson, 2004). Organizational identity is defined as the values that bring together the employees in the organization and that the organizations have central, permanent and different characteristics and are shared by the employees. Hatch and Schultz (1997) designate organizational identity as the beliefs and experiences of the employees and how they express the organization. It is the attitude and behavior of the employee as an organization member towards his / her organization and another Organizational identity is the body of ideas that the organization has about itself. It is expressed as a situation that expresses how the organization positions itself and how it is perceived by other stakeholders and includes communication activities for organizational image (Dutton, Dukerich, \& Harquail, 1994).

Different scientists have various perspectives on how to explain these features. Many consider what is an organizational identity or how it should be (Corley et al., 2006; Gioia, Schultz, \& Corley, 2000; Haslam, Cornelissen, \& Werner, 2017). Research on organizational identity show that it is not enough to understand the identity process only with cognitive concepts of identity (Brown, 1997), consequently psychoanalytical can provide an in-depth understanding of the organizational identity process. Unlike the previous section, organizational identity will be depicted from Lacan's perspective, which emphasizes the importance of language, broadens and broadens Freud's theory, and gives a new perspective (Lacan, 2001). Organizational identity is due to its discursive nature could understand if focused on discourse, that is the main reason for choosing this theory. Whetten (2006) define organizational identity as a discourse of main, distinctive and consistent features of organization, which is formed not only by internal but also by external collaborators. That discourse encompasses varying degrees as individuals can benefit from organizational or collective discourse to build an identity for themselves and, accordingly, individual narration contributes to the collective discourse. As a result, the discourses of organizational identity differ from the discourses of individual identity, and these two are commonly formed (Brown, 2001). In the light of this knowledge, it can be explained how individuals construct subjectivity in the discourse, and it forms a discourse of organizational discourse and vice versa, it can be argued that organizational discourse is included in the imaginary construction of identity and organization. Especially, organizational identity is constructed in the collective discourse as social construct (Haslam et al., 2017), approved by imaginary conscious identity, ordinarily constructed by individuals (Gioia, Schultz, \& Corley, 2000). This illusory organizational identity indicates the organization as what we want and who we are and is built on a conscious imaginary order.

Previous studies (Albert \& Whetten, 2004; Hatch \& Schultz, 2002) on organizational identity have suggested the idea of conscious identity or how cognitive identity insights, but these studies are not sufficient to address processes of unconscious identity, and for that reason the addition of 
psychoanalytical understanding is momentous. The basis of this understanding is grounded on the Lacanian psychoanalytical approach. This point of view emphasizes language, the uncertainty of identity and desire. What has not been discovered so far in the practice and theory of organizational identity is that all this identity is an imaginary character. It is established around the fantasy or illusion that the self can be identified and implemented with the organizational identity; anyhow of either its organizational identity is homogeneous or heterogeneous, singular or plural, permanent or temporary. According to Lacan (1991), organizational identity means a conversation that can include socially constructed, internal and external stakeholders of the narrative structure of discourse or the fundamental, permanent, evident and unique features of the organization. Considering possible unconscious intentions, desires in the business environment, a synthesized understanding of organizational identity is revealed (Pedersen \& Kristensen, 2019). Organizational identity remained the focus of attention for a lot of research, these research have defined organizational identity as the essence of the organization, as distinctive and permanent, but studies based on discourse, rendered these criterions dysfunctional and refuted. According to critical psychoanalysis, studies that have been done before may ignore or avoid seeing the discursive aspect, but it is inevitable to reveal the material non-subjective nature underlying the concept. Such conceptual structures can also be seen as a narcissistic defense against the anxiety to perform identity or empty-self of the managerial position of the organization. From this point of view, the basic distinctive and permanent quality of modern organizations consists of struggles to survive in any material or ideological way. The imaginary nature of organizational identity discourse maintains a glimpse of the latent dynamic. Studies show that consistent, holistic and stable, fragmented, plural and dynamic identities are needed within the organization. It compares to two different points of view, individual and collective: the individual cannot be delineated as a subject within the organization, therefore collective includes each individual as many subjects. The links between individual and organizational identity is a process, a way of providing power and control in organizations, as well as uncertainty of identity discourse.

\section{Conclusion}

If we suppose that organizations are the social units of people, who are in a relationship with each other to achieve collective goals of their structure and at the same time they are managed by the leaders. Psychoanalytical approach to organizations can give a field a comprehensive understanding of their operation, but not from a treatment point of view because psychoanalysis is not only a clinical treatment method, except this is an important way to understand the psychology of groups and individuals. Psychoanalytic interpretation and perspective can bring both theoretical and practical novelties to research intended the organizations, and also may become more wide-spread. As Freud, Bion and later Freud's followers put forward: In organizations where people have a significant share of their social identity, they have a series of unconscious expectations such as fear, defense, addiction and attachment (Berman, 1995/1993). Psychoanalysis is a good standpoint to address the management of organizational processes and change, and the psychic powers that it reveals, with an emphasis on unconscious and emotional processes. Understanding Unconscious can help to explain how it can encourage individuals to see the most obvious shortcomings of planning and also encourage to reveal the most entrepreneurial and innovative solutions. Considering the organization and management literature, psychoanalytic studies are lacking. It is very important to shed light on new understandings and practices in the fields of organizational 
behavior, management, and contribute to the dynamic structure of the modernizing world, future research using psychoanalytical approach can bring new perspectives to the field.

\section{References}

Adorno, T. W., Frenkel-Brunswik, E., Levinson, D. J., \& Sanford, R. N. (1950). The authoritarian personality. New York: Harper \& Row.

Albert, S., \& Whetten, D. A. (2004). Organizational identity. In M. J. Hatch \& M. Schultz. (Eds.), Organizational identity: A reader (pp. 89-118). Oxford University Press.

Berman, E. (1993). Psychoanalysis, rescue and utopia. Utopian Studies, 4(2), 44-56.

Berman, E. (1995). On analyzing colleagues. Contemporary Psychoanalysis, 31(4), 521-539.

Bion, W. R. (1952). Group dynamics: A re-view. The International Journal of Psychoanalysis, 33, 235-247.

Bion, W. R. (1961) Experiences in groups and other papers. London: Tavistock Publications. [Reprinted London: Routledge, 1989; London: Brunner-Routledge, 2001.]

Brown, A. D. (1997). Narcissism, identity, and legitimacy. Academy of Management Review, 22(3), 643-686.

Brown, A. D. (2001). Organization studies and identity: Towards a research agenda. Human Relations, 54(1), 113-121.

Brown, W., Brown, W. B., \& Jaques, E. (1965). Glacier project papers: Some essays on organization and management from the Glacier project research (No. 8). United Kingdom: Gower Publishing Company, Limited.

Corley, K. G., Harquail, C. V., Pratt, M. G., Glynn, M. A., Fiol, C. M., \& Hatch, M. J. (2006). Guiding organizational identity through aged adolescence. Journal of Management Inquiry, 15(2), 85-99.

Davis, T. R., \& Luthans, F. (1979). Leadership reexamined: A behavioral approach. Academy of Management Review, 4(2), 237248.

Dutton, J. E., ve Dukerich, J. M., \& Harquail, C. V. (1994). Organizational images and membership commitment. Administrative Science Quarterly, 34, 239-263.

Empson, L. (2004). Organizational identity change: Managerial regulation and member identification in accounting acquisition. Accounting, Organizations and Society, 29(8), 759-781.

Ferenczi, S. (1988). Confusion of tongues between adults and the child: The language of tenderness and of passion. Contemporary Psychoanalysis, 24(2), 196-206.

Ferenczi, S. \& Jones, Ernest (Trans). (1916). Introjection and transference. In Contributions to psycho-analysis (pp. 30-79). Toronto, Canada: Richard G. Badger

Fraher, A. L. (2004). Systems psychodynamics: The formative years of an interdisciplinary field at the Tavistock Institute. History of Psychology, 7(1), 65-84.

Freud, A. (1936). Identification with the aggressor. The Ego and the Mechanisms of Defence, In the Standard Edition of the Complete Psychological Works of Sigmund Freud, 51, 117-131.

Freud, S. (1953). Wit and its relation to the unconscious (1905). In the Standard Edition of the Complete Psychological Works of Sigmund Freud, Volume 8. London: The Hogarth Press and the Institute of Psychoanalysis.

Freud, S. (1955a) Group psychology and the analysis of the ego (1920-1922). In the Standard Edition of the Complete Psychological Works of Sigmund Freud, 18, 65-144. London: The Hogarth Press and the Institute of Psycho-analysis.

Freud, S. (1955b). Totem and Taboo (1913-1914). In the Standard Edition of the Complete Psychological Works of Sigmund Freud, 13(1), 7-162. London: The Hogarth Press and the Institute of Psycho-analysis.

Freud, S. (1957). On narcissism: An introduction (1914-1916). In the Standard Edition of the Complete Psychological Works of Sigmund Freud, 15, 67-102. London: The Hogarth Press and the Institute of Psycho-analysis.

Freud, S. (1960). The Ego and the Id. (1923). In the Standard Edition of the Complete Psychological Works of Sigmund Freud, 19, 12-66. London: The Hogarth Press and the Institute of Psycho-analysis.

Freud. S. (1961a). Civilization and its discontents (1930 [1929]). In the Standard Edition of the Complete Psychological Works of Sigmund Freud, 21, 57-145. London: The Hogarth Press and the Institute of Psycho-analysis.

Freud. S. (1961b). On the history of the psycho-analytic movement (1914). In the Standard Edition of the Complete Psychological Works of Sigmund Freud, 14, 1-66. London: The Hogarth Press and the Institute of Psycho-analysis.

Fromm, E. (1966). Análise do homem [Analysis of man]. France: Biblioteca de Ciências Sociais. 
Gabriel, Y. (1997). Meeting God: When organizational members come face to face with the supreme leader. Human Relations, 50(4), 315-342.

Gabriel, Y. (1999). Organizations in-depth: The psychoanalysis of organizations. Sage.

Gardner. J. W. (1989). On leadership. New York: Free Press.

Gioia, D. A., Schultz, M., \& Corley, K. (2000). Organizational identity, image, and adaptive instability. Academy of Management Review, 25(1), 63-81.

Harter, N., Ziolkowski, F. J., \& Wyatt, S. (2006). Leadership and inequality. Leadership, 2(3), 275-293.

Haslam, S. A., Cornelissen, J. P., \& Werner, M. D. (2017). Metatheories and metaphors of organizational identity: Integrating social constructionist, social identity, and social actor perspectives within a social interactionist model. International Journal of Management Reviews, 19(3), 318-336.

Hatch, M. J., \& Schultz, M. (2002). The dynamics of organizational identity. Human Relations, 55(8), 989-1018.

Hatch, M., \& Schultz, M. (1997). Relations between organizational culture, identity, and image. European Journal of Marketing, 31(5/6), 356-365.

Hirschhorn, L. (1990). Leaders and followers in a postindustrial age: A psychodynamic view. The Journal of Applied Behavioral Science, 26(4), 529-542.

Hogg, M. A., \& Tindale, S. (Eds.). (2008). Blackwell handbook of social psychology: Group processes. John Wiley \& Sons.

Ivancevich, J. M., \& Matteson, M. T. (1999), Organizational behavior and management (5th ed). Irwin/McGraw-Hill, Boston, MA.

Jaques, E. (1989). Requisite organization. Arlington, VA: Cason Hall \& Co.

Jaques, E. (1995). Why the psychoanalytical approach to understanding organizations is Dysfunctional? Human Relations, 48, 343-49.

Kernberg, O. F. (1975). Borderline conditions and pathological narcissism. New York: Jason Aronson.

Kets de Vries, M. F. (2001). The leadership mystique. A user's manual for the human enterprise (1st Ed.). London: Financial Times Prentice Hall.

Kets de Vries, M. F. (2006). The spirit of despotism: Understanding the tyrant within. Human Relations, 59(2), 195-220.

Klein, M. (1946). Notes on some schizoid mechanisms. In E. Spillius \& E. O'Shaughnessy (Eds.), Projective identification: The fate of a concept (pp. 19-46). Routledge/Taylor \& Francis Group.

Kohut, H. (1984). How does analysis cure? New York: International Universities Press.

Kohut, H. (1985). Self-psychology and the humanities: Reflections on a new psychoanalytic approach. United Sates: WW Norton.

Lacan, J. (1991). Le seminaire de Jacques Lacan 1969-1970, Livre XVII: L'envers de la psychanalyse [Jacques Lacan's seminar 1969-1970, Book XVII: The reverse side of psychoanalysis]. Paris: Editions Du Seuil.

Lacan, J. (2001). Autres ecrits [Other writings]. Paris: Editions Du Seuil.

Le Bon, G. (1897). The crowd: A study of the popular mind. London: T. Fisher Unwin.

Levinson, H (1987). Organizational behavior and the underlying disciplines. In J. W Lorsch (Ed.), Handbook of organizational behavior (pp. 51-56). Englewood Cliffs, NJ: Prentice-Hall.

Levinson, H., Molinari, J., \& Spohn, A. G. (1972). Organizational diagnosis. Cambridge: Harvard University Press.

Maccoby, M. (1976). The gamesman. New York: Simon \& Schuster.

Marcuse, H. (1955). Hegel and the rise of social theory. United Kingdom: Routledge \& Kegan Paul.

McDougall, W. (1921). The use and abuse of instinct in social psychology. The Journal of Abnormal Psychology and Social Psychology, 16(5-6), 285-333.

Pedersen, M., \& Kristensen, A. R. (2019) 'Blowing up the pylon': The limitations to Lacanism in organization studies, seen from the perspective of Deleuze and Guattari. Culture and Organization, 25(3), $189-201$. https://doi.org/10.1080/14759551.2016.1230855

Reich, W. W. (1970). Bestiality in the dramas of Christian Dietrich Grabbe (Unpublished doctoral dissertation). University of Connecticut, United Sates.

Rosen, I. B. (2006). Wilfred trotter: Surgeon, philosopher. Canadian Journal of Surgery, 49(4), 278-280.

Scheidlinger, S. (1952). Psychoanalysis and group behavior: A study in Freudian group psychology. New York: Norton.

Schwartz, B. (2011). Practical wisdom and organizations. Research in Organizational Behavior, 31, 3-23.

Sharma, G. D., Aryan, R., Singh, S., \& Kaur, T. (2019). A systematic review of the literature about leadership and organization. Research Journal of Business Management, 13, 1-14. 
Sievers, B. (1999). Psychotic organization as a metaphoric frame for the socioanalysis of organizational and inter-organizational dynamics. Administration and Society, 31(5), 588-615.

Stokes, J. (1994). The unconscious at work in groups and teams: Contributions from the work of Wilfred Bion. In A. Obholzer \& V. Zagier Roberts (Eds.) (1961), The unconscious at work: Individual and organizational stress in human services (pp. 19-27). London: Routledge, 1994.

Trehan, K. (2007). Psychodynamic and critical perspectives on leadership development. Advances in Developing Human Resources, 9(1), 72-82.

Trotter, W. (1941). The collected papers of Wilfred Trotter FRS. London: Oxford University Press.

Whetten, D. A. (2006). Albert and Whetten revisited: Strengthening the concept of organizational identity. Journal of Management Inquiry, 15(3), 219-234.

Zaleznik, A. (1989). The mythological structure of organizations and their impact. Human Resource Management, 28(2), 267277.

Zaleznik, A. (2004). Managers and leaders: Are they different? Clinical Leadership \& Management Review: The Journal of CLMA, 18(3), 171-177. 